\title{
Ritualisation du changement et célébration des continuités : les cérémonies John Frum du 15 février à Tanna (Vanuatu)
}

Ritualization of change and celebration of continuities: John Frum's ceremonies

of February 15th in Tanna Island (Vanuatu)

\section{Marc Tabani}

\section{(2) OpenEdition}

\section{Journals}

\section{Édition électronique}

URL : http://journals.openedition.org/jso/7537

DOI : $10.4000 /$ jso.7537

ISSN : $1760-7256$

Éditeur

Société des océanistes

Édition imprimée

Date de publication : 31 décembre 2016

Pagination : 143-158

ISSN : 0300-953x

\section{Référence électronique}

Marc Tabani, «Ritualisation du changement et célébration des continuités : les cérémonies John Frum du 15 février à Tanna (Vanuatu) », Journal de la Société des Océanistes [En ligne], 142-143 | 2016, mis en ligne le 31 décembre 2018, consulté le 01 mai 2019. URL : http://journals.openedition.org/ jso/7537 ; DOI : 10.4000/jso.7537 


\section{Ritualisation du changement et célébrations des conti- nuités : les cérémonies John Frum à Tanna (Vanuatu)}

par

Marc TABANI*

\section{RÉSUMÉ}

Organisées annuellement depuis 1957, les cérémonies John Frum du 15 février à Tanna s'apparentent à une tradition inventée, conçue comme telle par ses initiateurs, puis revendiquée par leurs continuateurs comme l'emblème d'un "sauvetage de leur coutume". Empruntant initialement la forme d'une ritualisation d'expressions culturelles exogènes en vue de légitimer des orientations spirituelles inédites, cet événement revêtit dans la période post-coloniale une dimension plus politique et sécularisée. L'analyse de cette transition historique doit servir à replacer celle-ci dans un débat anthropologique plus large sur les questions de continuité culturelle et d'indigénisation de la modernité.

Mots-ClÉs : (néo-)ritualisations, traditions inventées, continuité culturelle, indigénisation de la modernité, île de Tanna, Vanuatu

Pour bon nombre d'habitants de la République de Vanuatu, le 30 juillet, date anniversaire de l'indépendance (1980), compte parmi les jours officiels les plus fédérateurs. Les autorités de ce petit État insulaire du Pacifique accordent à la fête nationale une priorité idéologique. Elles apportent, autant qu'il leur est possible, un soutien matériel et logistique aux principales manifestations se déroulant lors de ce rendez-vous annuel, dans la capitale Port-Vila et les principaux centres administratifs et commerciaux des îles dites

\section{ABSTRACT}

The John Frum ceremonies organized every 15th February since 1957 on Tanna have been considered an invented tradition by their first instigators. Later on, their successors claimed that this event symbolized the "salvage of their custom". Initially launched as a ritualization process of foreign cultural expressions, with the purpose of legitimating new spiritual directions, this event has taken a more political and secularized dimension in the post-colonial period. Analyzing this historical transition offers an opportunity to situate it within a broader anthropological discussion about cultural continuity and the indigenization of modernity.

KeYwords: (neo-)ritualization, invented traditions, cultural continuities, indigenization of modernity, Tanna island, Vanuatu

« extérieures». Cette fête représente un véritable modèle du genre, pour toutes les autres expressions collectives et festives d'un engagement citoyen. Jouant de la fibre patriotique comme d'un ressort idéologique, son objectif est de rappeler à un large public la synthèse unitaire des deux références constitutionnelles complémentaires sur laquelle se fonde l'affirmation d'une identité vanuataise l'ancrage dans les valeurs mélanésiennes, i.e. "la coutume $"^{1}$, et dans le christianisme. Toutefois, pour des raisons historiques liées aux turbulences

* Aix Marseille Université, CNRS, EHESs, CREDO, UMR 7308, marc.tabani@free.fr

1. La Constitution vanuataise ne mentionne pas explicitement la notion pidgin de kastom, qui est pourtant unanimement employée pour référer à ces valeurs, coutumes et traditions étiquetées " mélanésiennes ». Dans ce cadre bureaucratique d'un pouvoir d'Etat, la notion de kastom englobe à l'échelle nationale toute pratique, chose ou idée liée de près ou de loin aux anciennes cultures du pays, moralement acceptable par les principes chrétiens, et qui amène une contribution positive à l'unité du pays. Ainsi, l'agitation, en 1980, de groupes sécessionnistes se revendiquant de la coutume, fut considérée com- 
politiques et sociales qui ont accompagné l'accession à l'indépendance de cet exCondominium franco-britannique des NouvellesHébrides, les commémorations organisées en cette occasion ne sont pas nécessairement celles qui, dans certaines îles ou provinces, rassemblent les foules les plus importantes.

Il en va ainsi à Tanna, une île où depuis leur création en 1957, la remarquable popularité des cérémonies annuelles du 15 février ne fut jamais démentie. Seule l'organisation rituelle des grands cycles traditionnels du nekowiar ou nakwaiari (voir Guiart, 1956 ; Bonnemaison, 1996), plus rares et aléatoires, permettent d'y drainer autant de participants. Connu des Vanuatais comme le " jour de John Frum " (John Frum dei), du nom de l'esprit tutélaire de cette fête, ce grand rassemblement annuel très apprécié des gens de Tanna est, localement, plus sobrement appelé lafet blong fiftin (" la fête du quinze ") ${ }^{2}$. Après bientôt soixante ans d'existence, cet événement n'a sans doute pas reçu toute l'attention qu'il mérite, particulièrement concernant les aspects anthropologiques et historiques de sa remarquable récurrence. Même relatif, ce désintérêt est d'autant plus surprenant que ces cérémonies demeurent associées à l'expression des croyances en John Frum et aux passions suscitées par ce personnage mythique ${ }^{3}$, lesquelles firent pourtant le succès des écrits d'anthropologues ayant contribué à hisser ce mouvement au rang d'un des plus célèbres "cultes du Cargo " (Lindstrom, 1993). Une entreprise méthodique de déconstruction de cette catégorie (commentée notamment par Jebens, 2004 ; Robbins, 2004 ; Otto, 2009 ; Tabani, 2012 ;) s'est d'ailleurs employée ces dernières années à éliminer cette expression. L'étiquette " Cargo cult» ne serait qu'un stigmate conceptuel d'une anthropologie coloniale. Son usage résiduel devrait se limiter à une fonction signalétique : renvoyer à un pur label occidentaliste réservé à l'étude d'un "Soi occidental » (cf. McDowell, 1988 ; Kaplan, 1995 ; 2004 ; Hermann, 2012). Les fondements littéraires de ces critiques ne parviennent pas, pour autant, à occulter les innombrables observations factuelles rattachées à cette expression, ni à déprécier leur utilité dans l'analyse des changements culturels en Mélanésie. D'où l'enjeu pour l'anthropologie de se recentrer sur de réels processus sociaux, en revisitant des pratiques et institutions ayant déjà fait l'objet d'une riche couverture ethnographique.

Les cérémonies du 15 février furent, dans l'histoire coloniale de Vanuatu, les premières à avoir autant su renouveler des capacités d'identification collective, célébrer des loyautés primordiales inédites, et encourager par làmême leurs participants à contester toute forme de subordination aux autorités coloniales et aux Missions chrétiennes. Elles pourraient, sous cet aspect, être l'emblème d'un lien de continuité avec les dispositifs et objectifs actuels des politiques de célébration publique à Vanuatu. Ces célébrations annuelles apparaîtraient ainsi comme des communions proto-nationalistes qui préparent, et anticipent, celles qui marqueront, chaque année à partir de 1980, l'accession effective à l'indépendance d'une communauté nationale pensée en termes de communauté de culture. Des levers solennels de drapeaux et des défilés d'inspiration militaire viennent suggérer, dans le cadre de ces festivités, la ritualisation d'expressions culturelles contemporaines et la mise en scène d'orientations spirituelles sans précédent. Cette liturgie aux allures modernistes, accompagnée d'animations - danses, musiques, chants, pantomimes - dont le style l'est tout autant, font immanquablement penser à des traditions inventées, à ces compositions de facture récente, produits d'une histoire occidentale de la modernité, dont se sont fait l'écho des historiens $\mathrm{du}$ nationalisme (Hobsbawm et Ranger, 1983) et des anthropologues préoccupés par la question de la réification des identités culturelles dans le Pacifique ${ }^{4}$. Un air de famille commun à ces phénomènes semble ici d'autant plus flagrant que le caractère ré-inventé et novateur de ces cérémonies du 15 février est explicitement assumé par leurs initiateurs.

À l'inverse, en tant qu'inventions assumées ces cérémonies n'en présentent pas moins certains aspects qui pourraient également les rattacher à un ensemble de croyances et de pratiques

me «terroriste " par les nouvelles autorités du pays. De même, la sorcellerie, parmi d'autres pratiques pré-coloniales jugées négatives et condamnables, n'est pas incluse dans les valeurs affichées et revendiquées comme mélanésiennes et coutumières.

2. Il ne nous est pas possible, par manque de place, de présenter ici le déroulement complet de la fête John Frum du 15 février. Nous renvoyons le lecteur à la description détaillée donnée dans un précédent ouvrage (Tabani, 2008 :158-164). Depuis la création de ces festivités en 1957 à Sulphur Bay, sur la côte est de Tanna, le défilé de la Tanna Army, présentée comme une branche locale de l'US Army, en est le point d'orgue. Plusieurs dizaines d'hommes, torse nu, les lettres "USA » peintes en rouge sur leur poitrine, équipés de bambous effilés en guise de " fusils ", y paradent sur un rythme cadencé devant le drapeau américain.

3. Qui est John Frum, qu'est-ce que le Johnfrumisme ? Une bible ne suffirait pas pour répondre pleinement à ces questions. En résumé, il s'agit d'un esprit propre à une mythologie tannaise contemporaine qui au-delà des croyances en d'autres esprits, interpelle ses fidèles sur le sens à donner à leur « foi ». Révéré par eux au même degré que Jésus par les chrétiens, le message de John Frum se veut universel, mais dans les faits, aucun non-Tannais ne s'est jamais revendiqué de la croyance en John Frum.

4. L'interminable débat sur les politiques de l'identité et de la tradition dans le Pacifique, lancé par Keesing et Tonkinson (1982), prit un tour plus polémique lorsque la question d'une kastom ré-inventée fut associée à celle des idéologies nation- 
rituelles préexistantes, d'adaptations syncrétiques engendrées par plus d'un siècle de confrontation des cultures locales à la christianisation et à la domination coloniale. Sur bien des points, ces cérémonies semblent prolonger et entretenir des tensions et oppositions qui trouvent leur origine dans la période des premiers contacts ${ }^{5}$. Elles perpétueraient ainsi, sous des formes repensées et renouvelées, un lien culturel direct avec des structures pré-coloniales, et maintiendraient des codes symboliques faisant fonction de trait d'union entre le passé et le présent. Pour reprendre des formulations chères à Marshall Sahlins $(1992 ; 1999)$, on pourrait voir dans ces dispositifs de réinterprétation culturelle, les signes de vitalité et d'inventivité de cultures en lutte pour conserver leur autonomie face aux risques d'une occidentalisation galopante. Les cérémonies John Frum du 15 février, à l'image de phénomènes sociaux comparables en Mélanésie, relèveraient dès lors d'une tentative d'" indigénisation de la modernité " (ibid.), de maintien d'un ordre culturel au travers de changements sociaux radicaux. Le "pendant dialectique " à cette thèse (Babadzan, 2009: 179), la « modernisation de la tradition ", renvoie à l'usage d'éléments exogènes inédits pour établir une base idéologique à l'affirmation de liens de continuité avec le passé. Au terme de ce double processus herméneutique, l'attachement même à la kastom des cultures mélanésiennes amènerait ces dernières à se fondre dans une catégorie plus universelle et comparative des cultures populaires contemporaines (Akin, 2004; Scott, 2012) ${ }^{6}$. La question des sources d'inspiration de ces pratiques singulières et de leurs motivations profondes n'est pas non plus précisément tranchée par les gens de Tanna eux-mêmes. Des groupes villageois qui cultivent leur traditionalité et souhaitent une application plus stricte de la kastom, se qualifiant eux-mêmes de " coutumiers " (man belong kastom), refusent cette même étiquette aux adeptes de John Frum, du fait notamment de la pétulance néo-païenne dont se drape leur cérémonial. Pour des groupes plus modernistes, dont les membres ont été scolarisés et sont porteurs d'un christianisme plus orthodoxe, les croyances en John Frum et l'organisation rituelle qui leur est liée sont également perçues comme éloignées de ce qui, dans leur vision, serait conforme à la coutume. Toutefois, nul à Tanna ne conteste, en la figure mythique de John Frum, sa qualité d'emblème de l'engagement des man Tanna pour le "sauvetage de leur coutume" (Tabani, 2008). Les mots, les actes et les choses d'un monde selon John Frum n'appartiennent pas en soi à la kastom de Tanna, mais ils interferent avec sa réévaluation contemporaine. Ils font partie intégrante d'une période historique moderne de la kastom, à l'issue de laquelle le culte rendu à un esprit messianique a laissé place à la célébration populaire d'un héros mythologique, devenu pour les gens de Tanna une expression contemporaine à part entière de leur culture, et de l'identité partagée qui lui est sousjacente.

Pour préciser en quoi des néo-ritualisations telles que les cérémonies du 15 février participeraient à la naissance d'une culture populaire contemporaine, nous évoquerons quelques étapes historiques de ce processus. Certaines convergences entre des données historiographiques et celles tirées des traditions orales $^{7}$ doivent permettre d'éclairer les enjeux sociaux qui déterminèrent l'émergence puis l'institutionnalisation de ces manifestations. Sera ensuite brièvement abordée l'actualité ethnographique de ces cérémonies, afin de souligner les risques que font peser sur leur organisation de croissantes pressions globales. La folklorisation d'un patrimoine culturel, dans ces îles autrefois reculées, y est aujourd'hui devenue complémentaire de l'aliénation des terres et, plus largement, d'une marchandisation des modes de vie et des cultures indigènes (De Burlo, 1989; Keesing, 1996 ; Tiley, 1997 ; Tabani [nd]). L'exploitation des cérémonies John Frum à des fins commerciales, touristiques ou médiatiques à outrance est devenu, à Tanna, l'inquiétant reflet d'un tel processus.

Avant de revenir sur ces points, et pour avancer sur la question des liens d'ascendance que les cérémonies du 15 février pourraient, ou non,

alistes en Océanie (Babadzan, 1988 ; Keesing, 1989). Ce débat s'est vu depuis régulièrement alimenté par d'innombrables publications sur le sujet, au gré notamment des crises que traversent les processus d'édification nationale des pays de la région.

5. Les premiers contacts culturels soutenus et répétés à Tanna débutent avec les incursions des navires baleiniers, puis santaliers dans les années 1830, le séjour de Cook en 1774 n'ayant entraîné aucune transformation mémorable (Adams, 1984). Les prolégomènes du mouvement John Frum ont ainsi été orchestrés par une génération d'insulaires dont les parents avaient vécu l'arrivée et l'installation des premiers étrangers européens.

6. La reprise, par des idéologies modernes, d'éléments, pratiques et symboles estampillés kastom, puis la transposition de ces mêmes constructions politiques à des cultures populaires en formation - autrement dit, la manière dont ces fictions idéologiques nationales ont été intégrées à des réalités sociales locales -, est un point qui a été repris et discuté dans plusieurs publications (voir en particulier Akin, 2004, 2005 ; Babadzan, 2005 ; Tabani, 2012).

7. Mon travail de restitution et d'analyse des données concernant les célébrations du 15 février a été amorcé lors de précédentes publications (Tabani, 2007 ; 2008). Il est le fruit de quatre participations directes à ces cérémonies (1999, 2000, 2008, 2012) et de plus de deux décennies de recherches sur la question du Johnfrumisme, tant sur le terrain, que dans les archives néo-hébridaises du British Service (Auckland et Port-Vila) et de la Résidence de France (Nouméa et Aixen-Provence). 
entretenir avec les formes actuelles de célébrations publiques et leurs aspects néo-rituels, il semble utile d'offrir au préalable quelques aperçus de ces pratiques contemporaines à l'échelle nationale de Vanuatu.

\section{Célébrations publiques à Vanuatu}

La vie publique à Vanuatu est rythmée par une succession de célébrations officielles, de fêtes légales, d'anniversaires, de commémorations, d'inaugurations, de journées et mobilisations à thèmes, de toutes sortes et en tout genre. Le spectacle offert en ces occasions plus ou moins festives obéit à un format habituellement très similaire. Il est fait de discours solennels, de cérémonies protocolaires, qui peuvent s'accompagner de débats, d'expositions, d'ateliers, de parades, défilés, cortèges, fanfares, d'animations ou de simples mondanités, fréquemment agrémentés de performances culturelles et artistiques. L'objectif affiché est de favoriser l'action collective en suscitant l'éveil citoyen, de mobiliser les foules autour de valeurs positives, générales et abstraites - la solidarité, l'entraide, la tolérance, la sagesse, la persévérance, le respect, le souvenir, la repentance, etc. Certaines de ces occasions peuvent également se prêter à des opérations caritatives, en vue de soutenir financièrement des initiatives associées à ces louables intentions. L'idéalisme affiché lors de ces rassemblements propitiatoires les distingue, en premier lieu, d'autres formes de liesses et démonstrations collectives qui opèrent dans le registre des jeux et modes de masse, comme celles par exemple qui accompagnent les grands événements à dominante sportive ou artistique.

Selebreson, seremoni, memori dei, pablik dei, lafet, aniveseri, festivol, fanresing sont les termes les plus courants en bichelamar (la langue créolisée nationale), pour évoquer ou décrire le fait de marquer un événement, de célébrer symboliquement des principes partagés ou de fêter cérémoniellement des projets parrainés par des institutions, des collectivités, des communautés, des associations. Aux temps coloniaux, de semblables festivités officielles furent simplement importées, depuis les métropoles respectives du Condominium franco-britannique des Nouvelles-Hébrides, pour maintenir le lien social entre ressortissants de leurs communautés respectives. À l'intention des populations indigènes, en revanche, comme dans bien d'autres contextes coloniaux, les fastes et les rites impériaux tenaient surtout lieu de démonstrations de force, pour illustrer la supériorité revendiquée du pouvoir des Occidentaux (Ranger, 1983). Dans un contexte post-colonial, le recours à ces mobilisations collectives à des fins unitaires est rapidement devenu partie intégrante des dispositifs idéologiques d'États souverains pour mobiliser leurs peuples (Gellner, 1989 ; Babadzan, 1988 ; Hobsbawm, 1992 ; Anderson, 1996). Suivant une logique voulue pleinement inclusive, celles-ci visent à réaffirmer et concentrer symboliquement, à l'occasion d'événements choisis, ce " plébiscite de tous les jours" (Renan, 1887) au cour des processus d'unification nationale. Une telle situation est toujours d'actualité dans un pays comme Vanuatu, où l'État demeure une réalité distante dans la vie quotidienne d'une majorité de la population (Miles, 1998), tandis que l'indépendance reste vécue comme récente et fragile - voire regrettable - par les générations plus anciennes ayant participé à son avènement.

Fêter l'année du dugong ou de l'économie coutumière, le jour des chefs, de la Constitution, de la violence contre les femmes, de l'AnZaC, de l'amitié avec la Chine ou l'Europe, participer aux banquets annuels de la Croix Rouge et du Rotary Club, demeure encore le plus souvent réservé à des milieux urbains cosmopolites. Leurs représentants se retrouvent lors de réceptions officielles autour de cocktails, au cours desquels se mêlent, dans une sociabilité bigarrée, politiciens, hauts fonctionnaires vanuatais et expatriés, hommes d'affaires et consultants, représentants de délégations diplomatiques ou d'ONG, hôtes de marque (scientifiques, artistes, reporters, etc.). Au cloisonnement colonial par castes s'est substituée, dans une sphère de happy few, la promiscuité entre élites. Invité un 14 juillet par la Résidence de France de Port-Vila, un collègue américain, observant les ripailles qui réunissaient le gratin mondain de la capitale, me fit ainsi part de ses impressions : "le Condominium n'est-il donc pas mort?" (Lamont Lindstrom, comm. pers.). La même remarque me fut adressée par un collègue britannique (Kirk Huffman, comm. pers.) au cours des grandioses festivités du trentenaire de l'indépendance, tant la continuité avec l'héritage colonial paraissait frappante dans l'esthétique protocolaire et l'apparat étatique ainsi mis en scène. Le constat partagé par ces deux témoins directs de la période des années 1970 à Vanuatu fut, un demi-siècle plus tard, celui d'une perpétuation de ces rites mondains importés du temps des Nouvelles-Hébrides, transplantés aux antipodes en même temps que les appareils bureaucratiques modernes auxquels ils venaient donner une touche exotique.

Toutefois, la répétition dece type de réjouissances mémorables ou de recueillements collectifs, de modèles festifs sécularisés initialement transmis par d'anciens cadres administratifs indigènes du Condominium, n'est plus l'apanage des seules élites dirigeantes ou du personnel politique national. Ces pratiques ont été progressivement 
mais largement popularisées, sans considération de classes sociales ni d'appartenances ethnoculturelles. Dans les années qui ont suivi l'indépendance du pays (surtout à partir d'une plus large ouverture politique et économique de celui-ci dans les années 1990), ces festivités et célébrations populaires modernes ont dépassé leur cadre urbain initial pour essaimer également vers les zones rurales. Culturellement, elles s'y sont même souvent vues plus indigénisées, plus détachées des réflexes consuméristes de la ville; l'imagination, la créativité et l'art de la débrouillardise venant pallier le manque de moyens matériels. Ainsi, le moindre établissement francophone du nord au sud de l'archipel se doit d'être au rendez-vous de la fête annuelle de la francophonie; dans chaque école du pays a été adopté et adapté un "jour des enfants "; chacune des sept Provinces dispose d'une date officielle pour réaffirmer son identité propre et honorer ses particularités régionales, voire insularistes; la commémoration des regrettés chefs d'État et autres leaders décédés ayant marqué la vie politique du pays tend, désormais, dans leurs communautés d'origines, à recouvrir les vestiges du culte des ancêtres, tout en lui empruntant ses règles de succession ${ }^{8}$.

Ces fêtes génériques ont diffusé à travers tout l'archipel, au prix d'une contextualisation sociopolitique de leurs enjeux et moyens, au point d'inspirer et d'entraîner dans leur sillage un lot d'initiatives strictement locales, répondant à des besoins toujours plus spécifiques. Toujours est-il que la principale caractéristique commune à ces temps forts du calendrier public, et aux manifestations ou démonstrations culturelles qui les accompagnent (souvent désignées en bichelamar par la formule kaljoral aktivitis - activités culturelles), est qu'ils ne se voient justifiés ni pour des raisons coutumières, c'està-dire prescrites et légitimées par la kastom, ni pour des exigences religieuses liées aux fêtes chrétiennes. Ce qui n'empêche pas de recourir pour leur organisation à des performances ou pratiques d'inspiration coutumière, des chants et des danses, ou ne serait-ce au minimum, la plupart du temps, pour les hommes présents, de se retrouver autour d'une coupe de kava, boisson nationale à connotation ancestrale. De même, organiser une cérémonie non-coutumière et séculière sans son lot de prières et d'hymnes serait vain, dans un pays fermement attaché à ses valeurs chrétiennes.
Malgré leur fréquente occurrence dans l'espace public, ces célébrations de conception récente n'occupent encore à Vanuatu que des segments chronologiques sécularisés secondaires, qui viennent sintercaler dans un calendrier religieux toujours largement dominé par les fêtes chrétiennes et les cycles cérémoniels ayant préexisté à la colonisation". Sans référence à une permanence du divin ou à la perpétuation de pratiques traditionnelles, elles maintiennent leur popularité à travers une logique de répétition, leur efficacité symbolique supposant leur récurrence. La fréquence et l'ampleur de ces rassemblements populaires, extensives au gré des besoins et des opportunités globales ou locales, reflètent la diversité des intentions de leurs ordonnateurs. Lorsqu'elles sont initiées à l'échelle nationale par des services ou institutions de l'État, ces manifestations peuvent se voir encouragées et soutenues financièrement par des organisations internationales, des agences d'aide au développement, des ambassades, des ONG ou grâce à du mécénat ou du bénévolat local de toutes sortes et de toutes dimensions. Au niveau provincial, insulaire ou plus localisé encore, s'ajoutent aux précédentes opportunités festives celles parrainées par des institutions provinciales, des partis, des associations, des clubs, des amicales et autres groupes aussi divers que variés.

Tournons-nous à présent, forts de ces éléments de comparaison, vers les politiques de célébration publique qui furent menées par les fidèles du mouvement John Frum. Que commémore-t-on le 15 février à Tanna, suivant quelle organisation, pour quels enjeux et dans quel registre s'inscrivent donc ces festivités?

\section{Commémoration d'une rébellion}

L'établissement à Tanna en 1905 de tribunaux chrétiens, composés de notables indigènes convertis, fit entrer l'évangélisation des populations de l'île dans une phase délibérément agressive. Après plus d'un demi-siècle d'efforts des missionnaires presbytériens, le rapport de force s'inversa rapidement en faveur des groupes christianisés. Une féroce persécution permit de réduire les ennemis de la Mission à une minorité ; jugés comme adorateurs des Ténèbres, ils étaient sévèrement châtiés, chaque fois qu'ils osaient encore se livrer à leurs pratiques traditionnelles.

8. On pourrait presque parler de la réinvention d'un système à titres électifs semi-héréditaires, vue la multiplication de successions intra-familiales au sein du personnel politique

9. Se voient ainsi exclues de ces cérémonies sécularisées les mises en scène de la coutume en tant qu' " art " (lors de performances réalisées à des fins touristiques ou lors de rassemblements unitaires, appelés kastom arts festivol ou kaljoral festivol), mais aussi les cérémonies de pardon et de repentance - au nom de la coutume - avec des individus, des groupes ou des institutions totalement étrangers à toute réalité coutumière (ces sori seremoni connaissent une inflation parallèle à celle de conflits et tensions que l'État n’arrive plus à contrôler ; pour le cas des îles Salomon, voir Fraenkel, 2004). 
La brutalité et les injustices qui caractérisèrent cette chasse aux païens lui valurent d'être désignée par l'expression Tanna Law, en référence à cette période d'humiliation restée gravée dans la mémoire collective comme la marque d'une suprême infamie. Des rapports administratifs postérieurs concèdent à propos des méthodes de la Mission, une "emprise totalitaire " digne de "l'inquisition espagnole ${ }^{10}$. L'instauration du Condominium des Nouvelles-Hébrides en 1906 ne fit que renforcer cette situation. Missions et administration se retrouvèrent unies dans leur détermination à briser toute forme de continuité culturelle. Délivrer « la bonne parole » chrétienne et porter l'action civilisatrice supposaient la disparition de traditions marquées par leur "sauvagerie" (anthropophagie, polygamie, fornication, meurtre de veuves, sorcellerie, etc.). Du passé, il fallait faire table rase, à commencer par les pratiques au cœur de la joie de vivre et du système de valeurs des idolâtres : des danses jugées obscènes et des ivresses collectives provoquées par un breuvage, le kava, aussi trouble que leurs âmes. Les seuls divertissements encore acceptés étaient ceux obligatoires et constamment réitérés, les chants et prières à l'office - « sing sing sing, pray pray pray all the time ", selon la formule d'un leader John Frum (Guiart, 1956 : 168).

Il fallut attendre la fin des années 1930 pour constater une première réponse concertée des man Tanna à la destruction programmée de leur ordre social et à l'effacement méthodique de leur horizon culturel. Avant de gagner en intensité, cette réaction indigéniste se déclara par de timides résurgences crypto-païennes, des fêtes interdites en brousse, à propos desquelles bruissaient de folles rumeurs. Des dignitaires coutumiers encouragèrent des convertis à participer à de fréquents rassemblements, tenus secrets des autorités, organisés dans des villages isolés. Ils attiraient un nombre croissant de curieux venus écouter des discours ou sermons, suivis de banquets puis de libations de kava, avant de clôturer ces sabbats nocturnes par des danses qui pouvaient se prolonger jusquau petit matin. Autant d'activités jugées parfaitement séditieuses par des autorités légales héritières du modèle et de l'idéologie de la Tanna Law.

Le délégué britannique pour Tanna, James Nicol, trouva dans un vol de chèvres le prétexte pour arrêter les quelques agités qui auraient fomenté la dernière de ces provocations, à la fin de l'année 1940, au lieu dit Green Point. Il s'agissait, pour l'administration, de marquer un coup d'arrêt aux rêves embrumés des nostalgiques de la vie d'autrefois, de les rappeler avec force aux nouvelles lois. La référence à un certain John Frum, personnage mystérieux, présenté comme la principale source de toute cette agitation, apparaissait toutefois secondaire dans les conclusions des premiers rapports de Nicol. Deux événements successifs allaient pourtant donner sa pleine dimension à toute cette affaire, pour les Blancs installés sur l'île. La fin avril 1941 fut marquée par un rush massif des man Tanna dans les quelques magasins de l'île, pour s'y livrer à des dépenses compulsives ; l'intention affichée était de dilapider tout argent disponible sur l'île afin de supprimer la cause exclusive de la présence d'étrangers. Puis, le dimanche 11 mai suivant, fut constaté un abandon en masse des églises; pendant des mois, voire des années les bancs de la skul (les églises et écoles de la Mission) furent presque totalement désertés.

L'histoire du mouvement John Frum présente toutes les apparences d'une rébellion anticoloniale - une révolte indigéniste, organisée et structurée, ciblant les Missions et les autorités condominiales, exprimant le refus de la domination d'étrangers sur Tanna. Dès ses premiers rapports, Nicol explique "l'affaire John Frum " comme une résultante "de l'idée habituelle qui veut que les indigènes de Tanna pourraient bien mieux administrer Tanna que je ne le fais moi-même" (ibid.: 152). Au-delà du zèle missionnaire qui aurait été un facteur déclencheur, les premières notes de synthèse des autorités du Condominium font état d'une détérioration des conditions économiques liées à la guerre. La chute des cours du coprah et le manque d'approvisionnement des magasins détourneraient les man Tanna du travail rémunéré, les enfermeraient dans la paresse et les encourageraient à une oisiveté propice à ressasser des sentiments anti-Blancs. La situation reviendrait à la normale lorsque les conditions favorables au commerce, au travail et à la consommation en milieu indigène se verraient restaurées. Les ferments nationalistes perçus à Tanna pouvaient apparaître comme universels, si ce n'est qu'en guise d'idéologie il était alors question d'un "retour vers les Ténèbres" (back to darkness) et de prophéties conduisant à une prolifération de nouveaux mythes et à la fabrication de néo-rites. Le rêve unitaire des man Tanna, fondé en raison, se voyait entravé par ces croyances insensées en la venue d'un Sauveur mystique.

Après un demi-siècle de répression des groupes païens sous la Tanna Law, s'ajoutèrent deux décennies supplémentaires de sanctions effrénées envers les partisans de John Frum, auxquels s'était ralliée une large majorité de la population. Évoquer, invoquer ou célébrer cet ostensible fantôme fut passible de prison, de l'exil ou des deux à la fois. Les danses et les beuveries de 
kava étaient les plus visées; jugées malsaines, indécentes, et donc subversives, ces festivités devaient cesser. Qui osait se revendiquer d'idoles néo-païennes encourait les foudres des autorités coloniales. Certains leaders de ce mouvement, passèrent des années en prison puis en déportation, et d'autres n'en revinrent jamais. William Nakomaha de Sulphur Bay cumula dix-sept années de peines ${ }^{11}$. Jamais pourtant, l'insoumission des leaders et partisans de John Frum ne faiblit.

Au-delà d'un possible retour hic et nunc de John Frum, le 15 février 1957 devait réserver une surprise. Ce vendredi-là, furent hissés à Sulphur Bay deux drapeaux rouges, par une garde d'hommes en bas de treillis, torse nu, avec sur leur poitrine et leur dos inscrit l'acronyme «T.A. » pour Tanna Army ${ }^{12}$. La mythologie John Frum relate que ces bannières avaient été remises à Tommy Nampas, autre leader du mouvement, par les big men d'une armée américaine qu'un millier d'hommes de Tanna avait rejoint en 1942, pour travailler sur sa base aéronavale de l'île d'Efaté. Ce don était supposé confirmer une prédiction, selon laquelle l'Amérique (Amerika, i.e. les États-Unis) était venue rendre aux man Tanna la liberté d'honorer leur coutume ${ }^{13}$. La mise en scène cérémonielle d'une résistance culturelle prit, ce jour-là, une tournure inattendue. Frappées de découragement devant tant d'obstination, les autorités coloniales décidèrent de laisser faire cette manifestation qui rassembla une foule de 2000 personnes (soit le tiers des habitants de l'île à cette époque). La milice formée par Nakomaha, auto-désigné général, défila les jours suivants de village en village. Les hommes qui la composaient, équipés de bambous effilés peints en rouge en guise de baïonnettes, faisaient penser à des combattants de la liberté venant de franchir leur premier pas vers l'indépendance. Selon les rapports administratifs de l'époque, on aurait assisté, à cette occasion, à la transformation d'un culte prophétique antiBlancs en un mouvement nationaliste :

"Vendredi 15 février 1957 deux drapeaux rouges furent hissés à deux très hauts mats de bambou, dans le village d'Ipekel à Sulphur Bay, et la nouvelle fut immédiatement diffusée que les gens de Tanna devaient venir voir leurs drapeaux censés symboliser la "Nation de Tanna ». [...] Les drapeaux sont en train de devenir l'objet d'une vénération, d'une loyauté à toute épreuve. "John Frum " a ordonné, d'après Nakomaha, qu'à chaque repas et notamment lorsqu'est bu le kava au coucher du soleil, des prières soient adressées à leurs drapeaux sur lesquels reposent l'unité de Tanna et la foi des gens dans la réalisation de leur aspiration nationale. Il a été entendu que certains indigènes avaient juré de protéger leurs drapeaux au péril de leur vie, si le Gouvernement voulait les retirer (rapport du BDA Challons, John Frum activities at Sulphur Bay, since the 15th February 1957) ${ }^{14}$ ".

Les rapports administratifs des années suivantes viennent confirmer le succès et la capacité de mobilisation des cérémonies du 15 février, dont la célébration allait se poursuivre sans interruption jusqu'à nos jours. Celles-ci ont depuis lors occupé une place centrale dans l'organisation du mouvement John Frum. À la faveur d'un abandon de sa répression et d'une formalisation de ses pratiques commémoratives et festives, elles lui ont localement et globalement servi de vitrine. Les performances néo-rituelles et les activités culturelles, dont la parade de la Tanna Army et le salut aux drapeaux au premier

11. Nakomaha est décrit parmi d'autres leaders comme «l'idéologue du lot » inspiré par « l'aspect unitaire et nationaliste de la prédiction de John Frum ; à l'avènement du Messie, le bloc de Tanna se trouverait un, sans fissures et hors la présence des Blancs » (Guiart, 1956 : 168 ; voir également MacClancy, 2007).

12. Une exégèse souvent paranoïaque des symboles John Frum par l'administration fut suivie de plaintes à l'égard de la référence à une "armée tannaise". Par compromis, les leaders du mouvement firent ajouter la mention USA (TA-USA) sur le torse des hommes, pour ensuite ne conserver que "USA ", évitant ainsi des barbouillages illisibles. C'est pourtant le délégué Nicol qui donna le plus de crédit à cette affaire de drapeaux, en menant dès 1942 une véritable traque pour retrouver ces bouts de tissus dont Nampas revendiquait la possession et qui auraient été déployés au grand jour quinze ans plus tard.

13. «Vila est plein d'Américains. D’autres, en plus grand nombre viendront jusqu’à Tanna. Les dollars américains sont la nouvelle monnaie annoncée. Les Américains sont des noirs. Ils vont bientôt gouverner les îles, libérer les prisonniers et leur paieront des gages. Voilà ce qu'on dit sur l'île " (Nicol, In the matter of Jonfrum, 10/07/42, NHBs 17/II/2). «Pratiquement tous les Tannas sont prêts à s'en aller. Ils croient dur comme pierre que Jonfrum va venir d'Amérique, aussi sont-ils trop heureux de l'aider. Il est inutile de discuter avec eux " (Nicol, lettre du 13/08/42, NHBs 17/II/2). La venue des Américains aux Nouvelles-Hébrides pour aider les gens de Tanna a été " prophétisée » pour la première fois en septembre 1941, soit trois mois avant l'attaque japonaise sur Pearl Harbor.

14. 26/02/1957, NHBS 4/III 12/2/1 vol.1. Une version alternative à l'origine des drapeaux est qu'ils aient été directement remis par John Frum : «John Frum aurait montré à Koukare, Sam Nakòo et Nambas, un drapeau sur lequel on veut qu'il y ait eu des étoiles; il leur aurait demandé s'ils le voulaient, à quoi ils auraient répondu affirmativement en levant le bras. John Frum aurait demandé alors s'ils accepteraient de mourir, dans le cas où les "Anglais " voudraient les tuer à cause de ce drapeau ; à cela, ils auraient répondu affirmativement de la même manière. Ce n'est qu'après cette scène historique que John Frum, assuré de l'appui des principaux notables, aurait fait inviter tout le monde à venir le voir. La légende veut même que Koukare ait désigné sur le dictionnaire à Nicol le drapeau de John Frum ; à cette vue, Nicol aurait tapé du pied et juré après son assesseur, lui montrant un fusil et lui disant : "Voilà ta nourriture » (Kaikai belong you)» (Guiart, 1956: 169). 


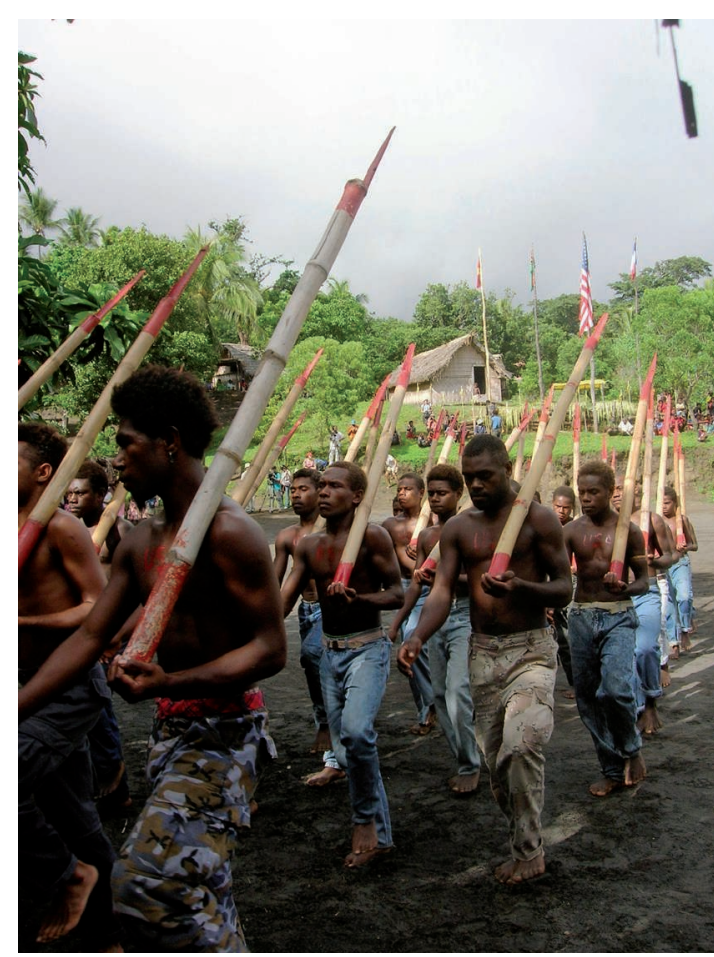

Рното 1. - Défilé de la Tanna Army à Sulphur Bay, Tanna, 15 février 2005 (cliché du TAFEA Kaljoral Senta)

chef, devinrent sa marque de fabrique, un support iconique qui gagna progressivement une notoriété internationale.

\section{Danser pour hâter la fin des temps}

En réalité, cette victoire inattendue fut aussi singulière que les méthodes de lutte qui l'avaient rendue possible. Il n'y eut aucune situation insurrectionnelle durable, sinon dans les fantasmes de colons prédisant une liquidation sanglante des Blancs présents sur l'île. Cette rébellion demeura non seulement non-violente dans la forme, mais sur le fond, les conceptions tannaises d'une indépendance politique restèrent obstinément frappées du sceau du surnaturel. La défaite du kapman (le gouvernement) et de la skul (la Mission) fut interprétée comme le signe d'un retour désormais proche de John Frum, lequel viendrait annoncer l'avènement d'un monde nouveau, littéralement transfiguré, où allait régner l'abondance, dans lequel les morts reviendraient à la vie, tandis que les vivants accéderaient à l'immortalité. Le "retour vers les Ténèbres ${ }^{15}$ devait réciproquement permettre l'accomplissement des promesses de John Frum, à savoir l'appropriation de tous les symboles $\mathrm{du}$ pouvoir des Blancs, leur organisation politique (gouvernement, police), leurs capacités technologiques (électricité, acier, moyens de transports) et leur abondance matérielle (argent, magasins et marchandises). Disposer, grâce aux pouvoirs de John Frum, des biens réservés aux étrangers, se débarrasser de ces derniers, et réinstaurer les lois de la coutume, formaient un triple enjeu qui ne souffrait, aux yeux des fidèles, d'aucune contradiction.

Au cours des années 1950, la lutte pour le retour à la coutume fut portée par des groupes convertis de la côte orientale de Tanna, anciens partisans de la Tanna Law ayant abandonné l'Église au cours des années 1930. Plusieurs des principaux leaders des districts de White Sands, de Sulphur Bay et de Port-Résolution avaient occupé des fonctions élevées dans la hiérarchie de l'Église presbytérienne ou adventiste locale. Toutefois, le fait d'avoir en grande partie perdu leurs pratiques coutumières et leur savoir traditionnel ne les empêcha pas de fonder la principale et plus active branche du mouvement John Frum. Leur stratégie consistait à associer l'idée d'une réalisation de la coutume avec celle du retour de leur Messie. Plus œcuméniques que leurs concurrents, ils entendaient, au moyen de ce dépassement syncrétique des traditions locales et du christianisme, révéler au monde que " la coutume était Lumière ». Et la fin des temps allait venir confirmer le savoir des man Tanna au sujet de l'origine du monde, en dévoilant que depuis le commencement, Dieu et la coutume participent d'une seule et même essence.

Pour accompagner et médiatiser ces espérances, fut lancée dès 1956 une véritable campagne de festivités en brousse. La glorification des pouvoirs de la coutume au travers du retour messianique de John Frum devait se préparer toujours et encore par des danses et des libations de kava. Mais pas n'importe quelles danses. Des danses mixtes, où hommes et femmes (y compris des jeunes non mariés) se livraient à des chorégraphies inspirées de celles observées parmi les Européens (à PortVila ou dans des films), qui se poursuivaient des nuits entières, parfois même sur les grandes places de danse traditionnelles ${ }^{16}$, pour appuyer l'idée que John Frum ou la coutume, c'était la

15. Formule initialement tannaise considérée comme participant d'une propagande John Frum, toute allusion à un " retour vers les Ténèbres » fut également sanctionnée. Elle est régulièrement mentionnée dans les rapports des délégués du Condominium, pour décrire les aspects régressifs du mouvement, " des efforts qui l'accompagnent pour revivre d'anciennes et indésirables coutumes" (Barrow, 1952:382) ; « il y a fort engouement, spécialement en brousse, pour revenir aussi loin que possible à l'ancienne voie païenne et déraciner le moindre reste de l'influence de la Mission " (BDA Colley, Jonfrum Report, 30/06/1949, NHBS 17/II/4 12/27/5).

16. Imwarim ou iimwaiimw, en langues vernaculaires, nakamal en bichelamar, est la place de danse cérémonielle. Lieu d'échanges et de sacrifices, elle est totalement interdite aux femmes du crépuscule aux aurores, quand les hommes s'y livrent quotidiennement au rite du kava. 


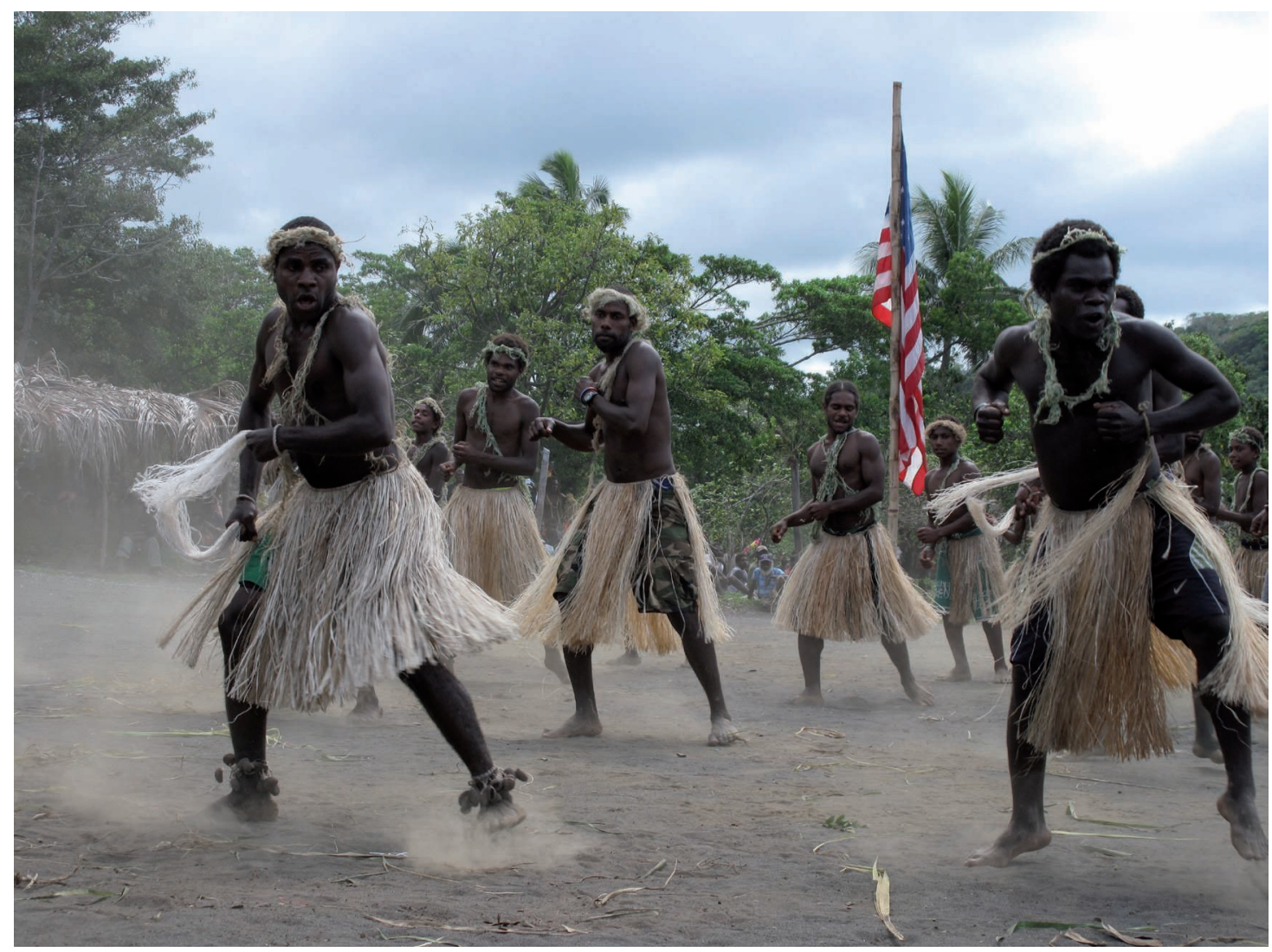

Рното 2. - Danse festive néo-coutumière lors des cérémonies John Frum du 15 février à Sulphur Bay, Tanna (cliché de l'auteur)

même chose. Leur accompagnement musical, sur fond de guitares et de ukulélés, s'avérait lui aussi de facture étrangère. De même pour les chants, qui étaient entièrement centrés sur une vision John Frum du monde, mais directement inspirés des hymnes chrétiens ${ }^{17}$. À partir de 1957 est venu s'ajouter à ces dispositifs cérémoniels tout l'attirail pseudo-militaire et philo-américain (lever des drapeaux et défilé de la Tanna Army).

Depuis cette date, le 15 février offre annuellement une présentation de toute la palette des innovations John Frum imaginables : des discours officiels, des prières syncrétiques, des banquets gratuits, des sketches et danses comiques, des pantomimes, des reconstitutions de scènes historiques. Le défilé de la Tanna Army peut comporter d'éphémères innovations (parade en 1978 d'une cavalerie, lever d'un drapeau " américain » en 1958, adjonction en 2000 d'une fanfare militaire, participation occasionnelle de brigades sans bambou ni référence à l'Amérique, attestant des diverses sensibilités coutumières envers le néo-paganisme du mouvement John Frum). Occuper symboliquement l'espace par le déploiement d'une nouvelle esthétique saccompagne également d'une tentative de prise de contrôle sur le temps. La fréquence des festivités obéit à une périodicité calquée sur le découpage calendaire et les représentations de la temporalité introduits par les Européens. Des fêtes furent organisées tous les vendredis, puis à partir de 1956, s'enchaînèrent de grands rassemblements, véritables meetings millénaristes, pérennisant la vision eschatologique d'un retour à la coutume.

Mais l'innovation majeure consiste, dans le cas John Frum, en cette capacité rituelle à gommer le caractère importé de ce qui pourrait apparaître comme des inventions, à dépasser par mimesis la nouveauté - la désavouer en lui faisant revêtir les habits passés d'une tradition pourtant méconnaissable. Les ukulélés, les guitares, les danses tropicalisées auraient déjà existé du temps du Noa tannais, le Noé biblique indigénisé, avant qu'il ne prit son départ de Tanna avec l'Arche ${ }^{18}$.

17. «La tradition s'est établie à Ipëkël de créer de nouvelles danses pour accompagnement de guitares; ces danses s'exécutent à deux groupes se faisant face à face sans se mélanger, dessinant sur le sol des figures collectives, ou entourant la figuration mimée d'un danseur individuel ou d'un petit groupe de participants. Un thème populaire fin 1952 était la course de taureau et la samba vue à la projection du film en couleur 'Fiesta'. La samba n'était alors mimée que par des danseurs hommes » (Guiart, $1956: 170$ ).

18. Le thème du Noa tannais, et plus généralement de l'identification de Tanna avec le paradis de la Genèse, est une des inventions mythologiques typiquement John Frum. Motivées au départ par des considérations pratiques, elles viennent 
Même chose pour la Bible, dont les man Tanna auraient déjà connu les enseignements bien avant l'arrivée des Blancs, ce qui légitimait l'abandon de l'école et de l'instruction. John Frum fut identifié à des esprits tannais, tels Karapanemun ou Whungen, et la Tanna Army, elle-même considérée comme la composante visible d'une armée d'esprits tapis dans le volcan Yasur, hautlieu des traditions tannaises.

Aussi avant-gardistes que paraissaient tant la mythologie de ce mouvement que ses pratiques cérémonielles, celles-ci véhiculaient une traditionalité, dont la validation reposait sur « les précédents du passé ». Elles demeuraient sous l'emprise, pour reprendre l'argumentation de Max Weber, d'un "strict traditionalisme " qui régit la "domination traditionnelle", premier des ordres légitimes, dans le contexte duquel, en dehors de révélations prophétiques,

«il n'y avait aucune possibilité [...] d'instituer de nouveaux règlements, c'est-à-dire qu'on ne les regardait comme 'nouveaux' qu'à la condition de les traiter comme s'ils valaient en vérité depuis toujours, mais qu'ils n'avaient pas été discernés correctement ou bien qu'ils aient été temporairement obscurcis et désormais redécouverts » (Weber, 1995 : 73)

Le 15 févier 1957, d'importants dignitaires païens vinrent effectivement apporter aux leaders John Frum, à Sulphur Bay, des nekawa tapunga, des kavas cérémoniels remis habituellement dans des circonstances exclusivement rituelles pour honorer des alliances. Par ce geste fut entérinée la reconnaissance du mouvement néo-païen comme voix légitime dans la défense de la coutume. Jusqu'alors, tout en ayant accepté l'alliance avec ce mouvement cultuel, ces traditionalistes ne suivaient, strictement, que la coutume. Mais à partir de cet événement, ils s'engagèrent à participer à certains aspects de l'organisation cérémonielle et des dispositifs néo-rituels John Frum ${ }^{19}$. L'allégeance de nombreux chefs coutumiers n'équivalait ni à une inféodation ni à une fusion. Chaque groupe affilié au mouvement ou participant à son réseau d'alliances était libre de fixer ses propres seuils au retour à la coutume ou d'engagement dans la cause John Frum. On y usait "d'un discours chrétien pour restaurer le paganisme" (Brunton, 1981: 374), tout en traditionalisant ce qui pouvait apparaître chrétien ou importé.

Jusqu'à l'approche de l'indépendance, on n'entendit plus beaucoup parler du mouvement John Frum et de sa fête du 15 février. À

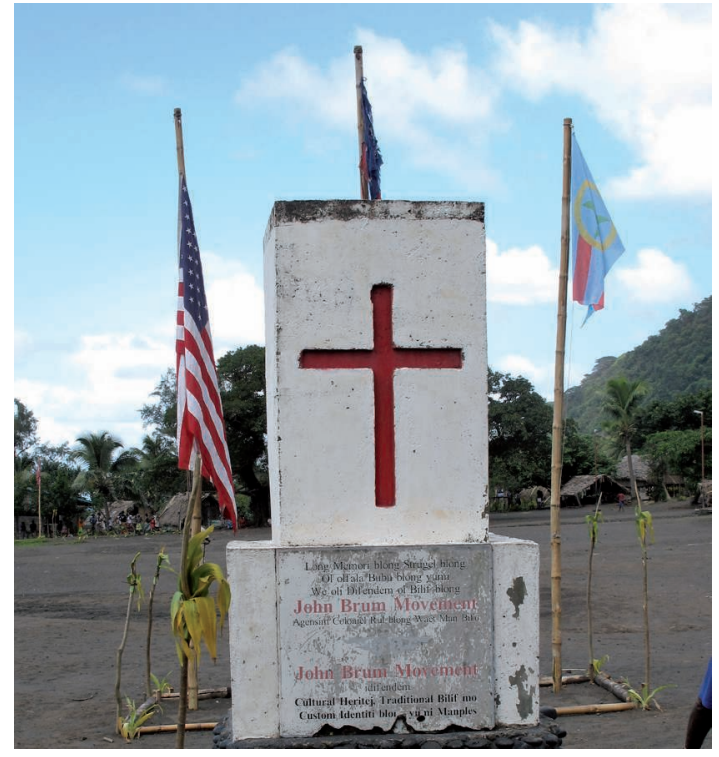

Рното 3. - Mémorial John Frum à Sulphur Bay, Tanna (cliché de l'auteur, 15 février 2012)

partir des années 1960 et jusqu'aux tensions indépendantistes de la fin des années 1970, ils cessèrent d'être un objet de préoccupation dans les comptes-rendus administratifs. Les références à John Frum elles-mêmes n'apparaissent plus que pour des troubles mineurs (des entraves ponctuelles à la présence d'étrangers, touristes, journalistes, scientifiques).

\section{Le 15 février, journée patrimoniale de la culture tannaise}

Vingt ans après l'accession à l'indépendance, un chef du gouvernement de cette jeune république vint pour la première fois assister à Tanna aux cérémonies du 15 février 2000. Il amenait avec lui la promesse de faire de cette date un jour férié national, en souvenir de la résistance menée par le mouvement John Frum contre le système colonial. Barak Sope, ancien idéologue de la lutte contre le Condominium, rappela qu'il s'était déjà rendu à Sulphur Bay, haut lieu du Johnfrumisme lorsqu'il n'était encore qu'un étudiant en recherche d'inspiration pour son engagement nationaliste :

ensuite s'ancrer à une vision cosmologique plus large. Ainsi, comme le note un rapport du délégué britannique, la nouvelle du retour de l'arche de Noa à son point de départ est une « fable destinée à atténuer les craintes des païens qui se rendent aux danses John Frum ; l'histoire veut que les guitares et les ukulélés étaient à l'origine des instruments de musique traditionnels que Noa leur avait enlevés pour les donner à l'homme blanc. Ce dernier, de retour à Tanna, a rapporté les guitares et les ukulélés chez eux " (Challons, 10/03/1958, NHBs 4/III 12/2/1 vol. 3).

19. Lorganisation du mouvement de Sulphur Bay repose notamment sur la participation de vingt-six groupes de musique (tim/team encadrés par des Bos, des Kapten et des Polis) placés chacun sous le patronage d'un des nombreux " fils de John Frum ", des esprits appelées koboe (cow boy) (voir Tabani, 2008). 
" Je suis venu parler avec le vieux Mweles et les autres anciens du mouvement John Frum. À cette époque, le Vanuaaku Pati n'était pas encore né, pas plus que le National United Party ou tous les autres partis. Il n'y en avait aucun. Seuls existaient les mouvements John Frum [à Tanna] et Nagriamel [sur l'île de Santo]. Et à l'époque, tous les anciens de ces mouvements avaient déjà discuté de l'indépendance, celle-là même dont nous disposons aujourd'hui. " (Discours enregistré le 15/02/2000)

Sope fut convié, en cette occasion, à inaugurer un mémorial. Ce simple monolithe en béton, orné d'un crucifix peint en rouge, comporte une petite plaque, sur laquelle on peut lire :

«En souvenir de la lutte menée par nos ancêtres pour défendre les croyances du mouvement John Broom contre la loi coloniale et l'homme blanc. Le mouvement John Broom, pour la défense de l'héritage culturel, des croyances traditionnelles et de l'identité coutumière des hommes de ce lieu " ${ }^{20}$

Cette déclaration d'un des pères de la nation vient marquer un second grand tournant dans l'histoire du mouvement John Frum. Après sa reconnaissance coutumière en 1957 , comme fer de lance dans la lutte pour la préservation de la kastom, vint le temps de son institutionnalisation nationale, au titre de précurseur du combat pour l'indépendance. Cette position de l'État à l'égard du mouvement John Frum représentait un virage idéologique à cent quatre-vingt degrés par rapport au traitement que lui faisaient subir, durant la première décennie d'indépendance, les gouvernements nationalistes. Pour avoir participé en juin 1980 à une tentative de sécession de Tanna, les John Frum furent marginalisés, reclus dans leurs bastions de la côte est, et considérés comme une secte d'illuminés présentant des difficultés à s’adapter aux réalités du monde moderne. La filiation revendiquée par Sope entre des néo-traditions millénaristes et une idéologie d'État, peut facilement être mise en doute au regard des analyses qui précèdent. Sauf à considérer que le contexte dans lequel s'expriment, depuis la fin des années 1990, les croyances en John Frum s'est sérieusement transformé. Et, effectivement, les points de rupture qui caractérisent cette période récente sont nombreux.

Ầ commencer sans doute, dans tout le pays, par une vive concurrence sur le marché de la foi (voir Eriksen, 2009) entraînée par la multiplication d'Églises néo-évangéliques jouant sur les peurs, comme celle d'une année 2000 signant la "fin du monde». On assiste également à un renforcement de l'économie de marché, à une accentuation du poids du tourisme, à une croissance des investissements étrangers particulièrement orientés vers l'accaparement des terres, et d'aides au développement prioritairement conditionnées par les intérêts des pays donataires. Dans cette période de doute, l'émigration salariale vers la capitale fait écho à une monétisation accentuée de l'économie rurale au détriment de l'horticulture vivrière. L'instabilité politique est relayée par une classe dirigeante trop souvent à l'affût d'avantages personnels. Les influences culturelles extérieures deviennent toujours plus pressantes dans le monde rural. La croissance démographique urbaine, la diffusion des moyens technologiques (transports, communication, médias) et la généralisation de la scolarisation jouent le rôle d'une caisse de résonnance pour l'amplification de ces pressions.

Ces ferments d'une crise sociale et culturelle allaient conduire à Tanna, à partir de l'an 2000, à un éclatement du mouvement John Frum, s'accompagnant de très fortes résurgences millénaristes. Au cours des années qui suivirent, le "mouvement de Fred ", une des factions les plus actives nées de cette scission, renoua avec un mode prophétique - reconstruction de l'Arche de Noé, réalisation hic et nunc des promesses de John Fum - et une organisation cultuelle encadrement des fidèles, frénésie cérémonielle - caractéristiques des néo-ritualisations et des mythologies syncrétiques, telles qu'elles avaient pris corps à la fin des années 1930. Entre ces deux grandes phases d'activité cultuelle placées sous le sceau de John Frum, séparées entre elles par plusieurs décennies, ce fut le sentiment d'une continuité qui domina unanimement chez les anciens du mouvement ayant participé à ses phases historiques.

Ainsi, dans le mouvement de Fred, la vie de tous les jours était rythmée par les discours visionnaires du prophète, par des offices religieux tenus sur un rythme quasi-quotidien, et par une attente rituelle ponctuellement consacrée par des destructions sacrificielles massives de bétail. Toutes ces occasions donnaient lieu à une suite ininterrompue de danses, de chants et de musique suivant le style typique des pratiques John Frum. L'expression cérémonielle des croyances demeurait intacte dans ses capacités de revitalisation. Toutefois, une source d'inquiétude devint palpable chez les fidèles de toutes obédiences, concernant le devenir des cérémonies du 15 février. À la question de savoir si celles-ci risquaient, dans les premières années de la prédication de Fred, d'être abandonnées, un de mes informateurs me donna la réponse suivante : 
"Cela dépendra de ce que les gens ont dans la tête. Mais si lafet s'arrêtait, ce serait une très mauvaise chose. Si quelqu'un osait l'arrêter, il porterait atteinte à la réputation de Tanna et à celle de tout le pays. Tanna est une petite île, [...] mais selon nos mythes elle fait tourner le monde [...] [elle est pour les] man Tanna à la source de leur pouvoir. Si quelqu'un voulait supprimer la célébration du 15 février, supprimer la mémoire de nos anciens et de John Frum, il se produirait quelque chose de grave. C'est devenu comme une religion pour nous. Pourquoi la supprimeraiton ? Si elle venait à disparaître nous deviendrions des fainéants, nous ne serions plus rien. " (Taniel Sarawe, Port-Résolution le 10/02/2002)

Les craintes ne sont cependant plus les mêmes que dans les années 1930. Le danger ne provient plus des risques de disparition d'une religion traditionnelle. Il pèse désormais sur certaines pratiques cérémonielles d'une néo-tradition religieuse originale, née de la confrontation avec le christianisme. Les menaces se concentrent particulièrement sur les cérémonies du 15 février pour différentes raisons. La principale est qu'elles emblématisent la dimension populaire d'un héritage patrimonial qui participe d'une identité tannaise contemporaine et de son image. Ce n'est pas l'ensemble de la mouvance John Frum, dans ses multiples branches (dont certaines contestent l'ascendant même de cette figure), qui se trouve engagé dans un processus d'institutionnalisation, mais bien les célébrations annuelles qui lui servent d'emblème. Celles-ci ont dorénavant été acceptées et reconnues par des non fidèles de John Frum et par des nonTannais, comme un élément à part entière d'un folklore local, participant d'une identité tannaise tantôt différenciée, tantôt partie intégrante d'un ensemble culturel national.

$\mathrm{Au}$ cours des événements troublés de l'indépendance, le mouvement John Frum réussit à fédérer sur l'île un camp dit "des Modérés ", composé de tous les groupes qui s'opposaient politiquement à Tanna, aux nationalistes anglophones et presbytériens du Vanuaaku Pati. Depuis lors, tout portait à croire que son aura de résistance se déplaçait sensiblement du terrain mystique vers ceux du politique et $\mathrm{du}$ culturel. En apparence, le mouvement semblait suivre la voie d'une sécularisation, marquée par la relance d'un parti politique John Frum et la nomination en 1999 - pour la première fois dans un gouvernement national, d'un Ministre de la santé élu sous cette étiquette. Les très fortes espérances millénaristes des fidèles du prophète Fred ont toutefois démontré les limites de la normalisation politique d'un mouvement John Frum unifié mais détaché des persistantes croyances de la masse de ses fidèles. Le mouvement de Fred s'est ainsi retrouvé aux avant-postes d'une contestation de toute forme d'institutionnalisation d'un patrimoine culturel John Frum qui ne serait plus porteur d'aucune attente spirituelle. Le rejet d'une telle patrimonialisation a conduit Fred à encourager ses fidèles à se détourner des cérémonies du 15 février. Néanmoins, malgré l'embrigadement dans son mouvement du quart de la population de l'île, il eut le plus grand mal à convaincre ses fidèles de renoncer au 15 février et à l'hommage rendu au drapeau américain. Même dévoyés, ces symboles appartiennent à l'histoire d'une vision de l'unité de tous les Tannais.

Les premières tentatives d'institutionnalisation du mouvement John Frum remontent aux années 1970. Elles découlaient d'enjeux politiques à la fois locaux et nationaux, pour lesquels les célébrations du 15 février servaient simplement de tribune. Vingt ans plus tard, ces cérémonies vont, de par leur valeur patrimoniale ajoutée, se retrouver au centre de toutes les convoitises. Avec l'ouverture économique des îles à un tourisme de masse, elles accèdent au rang d'attraction majeure pour les tour-operators et les visiteurs étrangers. La dimension politique d'une instrumentalisation de pratiques néorituelles leur conférant un statut d'institution populaire se voit reléguée, au cours des années 1990, derrière leur exploitation commerciale. Plus que le nombre de visiteurs, c'est un véritable matraquage médiatique qui s'abat sur le mouvement John Frum, avec des caméras invariablement braquées sur le 15 février, seul témoignage tangible des étranges croyances qui lui ont donné naissance. On ne compte plus les réalisations de films documentaires, de reportages journalistiques ou de programme de télévision des cinq continents qui, à l'intention de leurs audiences respectives, donnent à voir les croyances en John Frum, en se concentrant sur le caractère spectaculaire de ces cérémonies. Jacob Kapere, directeur à Tanna du Centre culturel de l'île, témoigne ainsi de cette situation :

"J'ai participé aux cérémonies John Frum depuis des années. Auparavant, très peu de touristes ou de journalistes y assistaient. En certaines occasions, il n'y avait d'ailleurs aucun visiteur étranger. Mais aujourd'hui, ils nous donnent l'impression de dépasser en nombre les participants locaux. De sorte que cette situation ne devienne pas un problème à Tanna, comme c'est déjà le cas sur l'île de Pentecôte [avec les cérémonies du saut du Gol], le Centre culturel de Tanna encourage les communautés villageoises à ne pas réclamer de l'argent auprès des visiteurs ou des équipes de tournage lors des cérémonies. Nous essayons d'évaluer localement les besoins afin d'offrir une aide matérielle. Le danger provient de la présence d'argent confié à quelques chefs et de l'absence de visibilité sur sa redistribution collective. Pour exercer ce contrôle nous pourrions écarter le tournage des films, mais pas les touristes ni empêcher le déroulement des cérémonies. » (Entretien du 15/02/2008) 


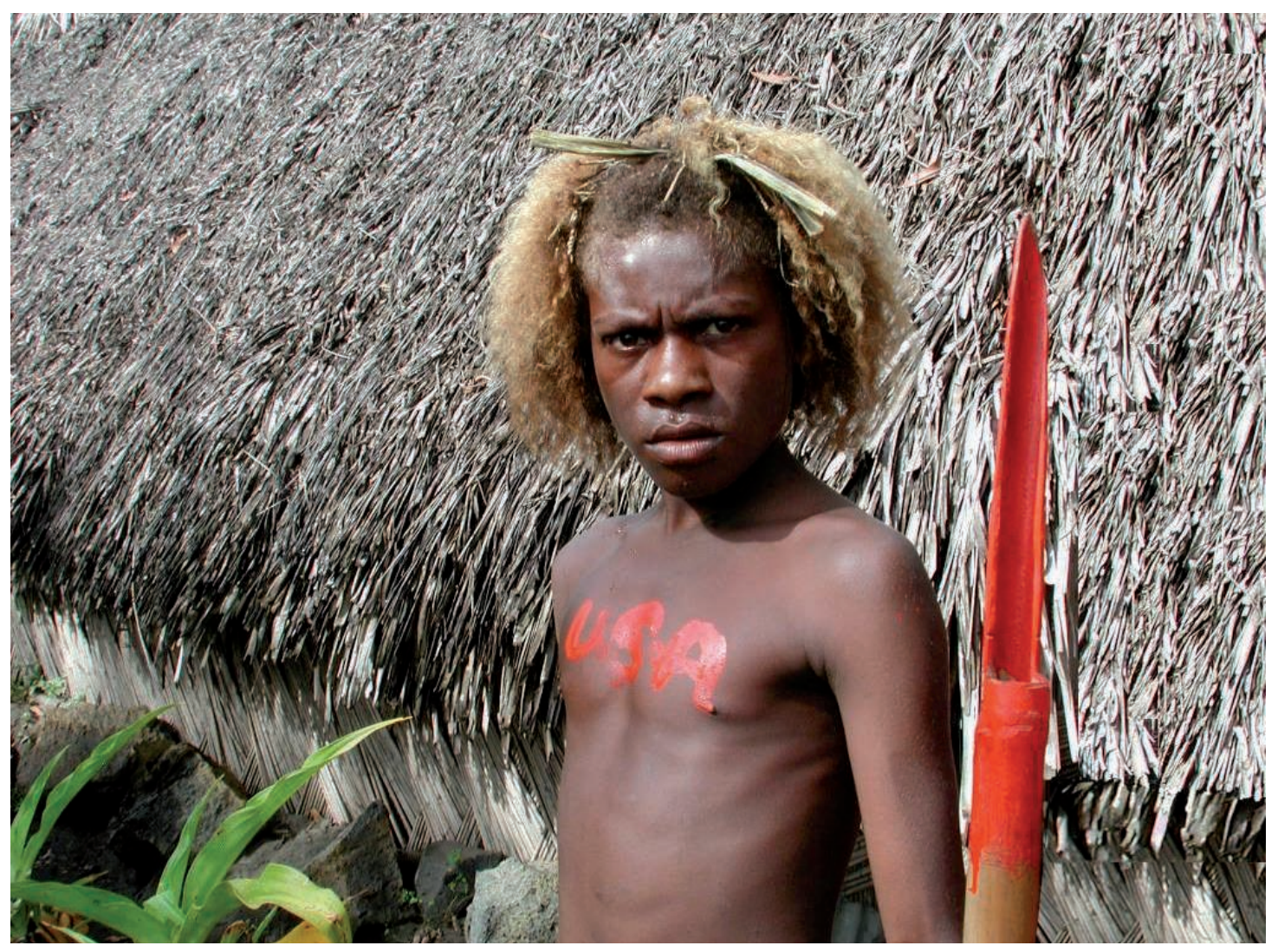

Рното 4. - Garçon de la Tanna Army lors des cérémonies John Frum du 15 février 2012, Sulphur Bay, Tanna (cliché de l'auteur)

Détourner des rites millénaristes en les réduisant à un folklore rentable amène à renforcer les aspects officiels de leur patrimonialisation ${ }^{21}$, mais également leur intérêt populaire - en tant que petit business pour des Tannais en quête des quelques miettes que représenteront leur part des bénéfices. L'esthétisation d'une originalité culturelle à des fins politiques obéissait à des enjeux internes à Tanna et à Vanuatu. Par contre, la surenchère de la médiatisation qui draine l'intensification de la commercialisation des cérémonies tend à échapper à tout contrôle, et devient un enjeu financier qui menace d'emporter leurs aspects religieux, culturels et patrimoniaux.

\section{Conclusion}

Après ces quelques aperçus historiques et anthropologiques sur les pratiques néo-rituelles du 15 février, revenons, en guise de conclusion, à notre interrogation initiale. Cet événement se distingue-t-il radicalement, ou à l'inverse préfigure-t-il ces commémorations officielles et ces célébrations publiques contemporaines qui ne relèvent ni directement de la coutume ni de l'Église? Il a été souligné que ces cérémonies sont nées à Tanna d'une volonté de dépasser une kastom "moribonde", dans l'intention de contester avec plus de détermination la loi de la Mission alors triomphante. La fin d'une répression systématique de cette lutte, qui coûta à certains meneurs des années de prison, signe la victoire du mouvement John Frum sur le gouvernement colonial, et enterre définitivement les entraves que posait la Tanna Law à une réhabilitation de la coutume. Dans l'intention de pérenniser les retombées de cet événement, le jour du 15 février fut choisi pour en hisser l'emblème le plus symbolique, le drapeau de la Tanna Nation, qui finira par se confondre avec la bannière des États-Unis. Car il s'agit bien d'une nation sans État, réfractaire à toute forme d'État, dont la célébration prend la forme d'un anniversaire à rebours. Ce n'est pas l'acte de

21. Ces aspects officiels d'une réification patrimoniale comprennent, en premier lieu, l'usage des normes juridiques et le recours aux tribunaux. Ainsi, en 2003, Isak Wan, leader de la branche John Frum de la côte est, saisit la Cour suprême pour se voir reconnaître un leadership sur l'ensemble d'un mouvement John Frum, afin de disposer des copyrights afférant au nom "John Frum». Affaire qu'il perdra au profit des représentants de la branche John Frum du sud-ouest. Voir Isaac Wan v Seth Kaurua [8 May 2006] vusC ; Civil Case 164 of 2003 (28 July). 
naissance de cette nation néo-coutumière qui est commémoré, mais la distance temporelle qui la rapproche d'un retour de John Frum et du rayonnement éternel de la coutume qui viendront marquer cette fin des temps.

Si John Frum n'est pas né de la seule coutume, il n'en demeure pas moins en phase avec un monde qui lui précède, sur au moins deux aspects fondamentaux qui ont structuré les orientations profondes de son mouvement. Il est intéressant de noter à cet égard la conclusion de la version confidentielle d'un rapport de Jean Guiart, après six mois d'enquête à Tanna en 1952-1953 :

«La tendance du mouvement John Frum est dirigée vers la formation d'une théocratie nationale néopaïenne, qui vient remplacer l'ancienne théocratie étrangère des presbytériens. »

Ce constat appuie l'idée que le personnage de John Frum endossait en fait les habits neufs d'une idole païenne. Les leaders du mouvement n'eurent de cesse, plutôt avec succès, de revendiquer une filiation de leurs singulières pratiques avec la coutume.

«En 1941, quelle que fut l'influence du mythe de John Frum à cette période, le mouvement consistait essentiellement en un retour aux pratiques païennes [...]. Le degré d'emphase porté sur le lien entre John Frum et la coutume, varie de l'attitude des jeunes supporters John Frum pour lesquels l'importance de la coutume a diminué, bien qu'elle ne soit pas rejetée, passe par les considérations des leaders John Frum qui revendiquent une parfaite équivalence entre John Frum et la coutume, jusqu'à la position des néo-païens qui dénient à John Frum tout lien avec la coutume et toute validité en soi. Mais il n'y a pas de divisions tranchées entre les groupes John Frum et les autres. Les différences de croyances sont brouillées [...]. La coutume tout comme John Frum sont brandis en défense contre les interférences [de l'administration et des Missions] dans les affaires tannaises, et utilisés comme un argument justifiant une non-coopération [avec les autorités]. » (BDA Allen, Notes. 12/07/1960. NHBs 4/III 12/2/1 vol.3)

À partir des années 1950, John Frum et la coutume se voient érigés au rang d'une loi (John Frum lo ou kastom lo), qui s'immisce dans toutes les affaires tannaises, et reprend à son compte les procédés et les intentions hégémoniques de la Tanna Law. Cette loi domine la vie d'une majorité des habitants qui partage les croyances sur lesquelles elle repose, et affecte également celle des groupes qui se montrent opposés ou neutres envers ses nouveaux commandements.

«Il y a d'évidents parallèles entre les anciennes structures de la théocratie presbytérienne de la pé- riode de la Tanna Law : la plus invasive des administrations que Tanna a sans doute jamais connu, avec son organisation centralisée, redescendant de manière effective jusqu'au niveau villageois [...] Des boss John Frum nommés pour chaque village [...], tout comme les Anciens (elders) le faisaient par le passé, s'immiscèrent dans des jugements qui ne portaient pas seulement au sein de ces tribunaux, sur des questions religieuses, mais également sur des affaires criminelles, sur le fondement que ces offenses étaient contraire à la loi de John Frum. » (Allen, ibid.)

La coutume et la Tanna law sont les deux sources spirituelles indissociables du Johnfrumisme qui en est un prolongement. En tant que tradition religieuse, ce mouvement a pris racine dans un contexte historique dans lequel une culture traditionnelle était en passe de succomber aux coups de butoirs de la christianisation. La production de néo-traditions visait à compléter et sauver ce qui pouvait l'être des survivances pré-coloniales, tout en rejetant du christianisme les conceptions faisant obstacle à ce renouveau de la coutume. Le 15 février permet d'en consacrer la victoire, par la mise en œuvre de nouveaux dispositifs cérémoniels de ritualisation du changement.

Pourtant, la célébration du 15 février comporte à l'évidence, au cours de sa perpétuation, une réelle césure. En se voyant progressivement séparée de l'univers de croyances dont elle est issue, celle-ci s'est progressivement retrouvée, au cours de son histoire récente, bien plus en phase avec les manifestations populaires qui lui succèdent qu'avec les motifs religieux qui l'ont produite. Le spectacle d'une patrimonialisation de ces cérémonies s'est substitué, dans les années 1990, aux anciennes mises en scène des traditions syncrétiques qu'elles donnaient à voir. La dimension populaire qu'elles gagnent au travers de cette rupture les place sur un même rang que des célébrations importées puis recontextualisées suivant les besoins festifs du moment. À l'instrumentalisation politique initiale de cet événement va massivement venir s'ajouter son exploitation commerciale. Les appels prophétiques et les fantastiques cargaisons promises par John Frum ont laissé place aux discours sur le développement d'invités officiels et aux distributions de pourboires des touristes. Comme pour d'autres occurrences cérémonielles populaires qui n'auraient jamais disposé de la légitimité d'un précédent, l'efficacité des cérémonies du 15 février se voit dorénavant assurée par le simple biais de leur répétition. Rompant avec d'anciens modes de perpétuation du passé, elles sont depuis lors dédiées à la célébration de continuités contemporaines, ancrées dans un rapport sécularisé à la culture. 


\section{BIBLIOGRAPHIE}

Adams Ron, 1984. In the Land of Strangers. A Century of European Contact with Tanna, 1774-1874, Canberra, The Australian National University, National Center for Development Studies, Pacific Research Monograph 9.

AkIn David, 2004. Ancestral Vigilance and the Corrective Conscience: Kastom as Culture in a Melanesian society, Anthropological Theory 4 (3), pp. 299-324.

_-, 2005. Kastom as Hegemony, a Response to Babadzan, Anthropological Theory 5 (1), pp. 75-83

ANDERson Benedict, 1996. Limaginaire national: réflexions sur l'origine et l'essor du nationalisme, Paris, La Découverte.

Babadzan Alain, 1988. Kastom and Nation-Building in the South Pacific, in R. Guidieri et al. (eds), Ethnicities and Nations, Austin, University of Texas Press, pp. 199-228.

_-, 2004. Commentary: Kastom as Culture, Anthropological Theory 4 (3), pp. 325-328.

_-, 2009. Le spectacle de la culture : globalisation et traditionalismes en Océanie, Paris, L'Harmattan.

Barrow G. Len, 1952. The Story of John Frum, rapport adressé à la Commission du Pacifique Sud, non publié, Port-Vila, Archives nationales de Vanuatu.

De Burlo Charles, 1989. Land Alienation, Land Tenure, and Tourism in Vanuatu, a Melanesian Island Nation, GeoJournal 19 (3), pp. 317-321.

Bonnemaison Joël, 1996. Les fondements géographiques d'une identité. L'archipel de Vanuatu, essai de géographie culturelle : histoire et géosymboles d'une société enracinée: Tanna, Paris, ORSTOM.

Brunton Ron, 1981. The Origins of the John Frum Movement: A Sociological Explanation, in M.R. Allen (ed.), Vanuatu: Politics, Economics and Ritual in Island Melanesia, Sydney, Academic Press, pp. 357-378.

Eriksen Annelin, 2009. "New Life": Pentecostalism as Social Critique in Vanuatu, Ethnos 74 (2), pp. 175-198.

Fraenkel Jon, 2004. The Manipulation of Custom: From Uprising to Intervention in the Solomon Islands, Wellington, Victoria University Press.

GuiarT Jean, 1956. Un siècle et demi de contacts culturels à Tanna (Nouvelles-Hébrides), Paris,
Société des Océanistes, Publication de la Société des Océanistes 5.

Gellner Ernest, I989. Nations et nationalisme, Paris, Payot.

Hermann Elfriede, 2012. The Yali Movement of Papua New Guinea: the Dialogics of Representation, in M. Tabani et M. Abong (eds), Kago Kastom Kalja: The Study of Indigenous Movements in Melanesia Today, Marseille, Pacific-Credo Publications, pp. 147-168.

Hовsвашм Eric, 1992. Nations et nationalisme depuis 1780, Paris, Gallimard.

Hobsbawm Eric and Terence Ranger (eds), 1983. The Invention of Tradition, Cambridge, Cambridge University Press.

Jebens Holger, 2004. Introduction: Cargo, cult and culture critique, in $\mathrm{H}$. Jebens (ed.), Cargo, Cult \& Culture Critique, Honolulu, Hawaii University Press, pp. 1-13.

Kaplan Martha, 1995. Neither Cargo nor Cult: Ritual, Politics and the Colonial Imagination in Fiji, Durham [N.C], Duke University Press.

_ 2004. Neither Traditional nor Foreign: Dialogics of Power and Agency in Fijian History, in H. Jebens (ed.), Cargo, Cult and Culture Critique, Honolulu, University of Hawai'i Press, pp. 55-79.

Keesing Roger M., 1989. Creating the Past: Custom and Identity in the Contemporary Pacific, Contemporary Pacific 1, pp. 19-42.

_, 1996. Class, Culture, Custom, in J. Friedman Melanesian Modernities, Lund, University Press, pp. 162-182.

Keesing Roger M. and Robert Tonkinson (eds), 1982. Mankind, Special Issue 13(4): Reinventing Traditional Cultures in Melanesia.

Lindstrom Lamont, 1993. Cargo Cult. Strange Stories of Desire from Melanesia and Beyond, Honolulu, University of Hawai'i Press.

McDowell Nancy, 1988. A Note on Cargo and Cultural Construction of Change, Pacific Studies 11, pp. 121-134.

MacClancy Jeremy, 2007. Nakomaha: A Counter-Colonial Life and its Contexts. Anthropological Approaches to Biography, Oceania 77 (2), pp. 191-214.

Miles William F-S, 1998. Bridging Mental Boundaries in a Postcolonial Microcosm: Identity and Development in Vanuatu, Honolulu, University of Hawai'i Press.

Ranger Terence, 1983. The Invention of Tradition in Colonial Africa, in E. Hobsbawm \& T. Rang- 
er (eds), The Invention of Tradition, Cambridge, Cambridge University Press, pp. 211-262.

Renan Ernest, 1887. Qu'est-ce qu'une nation?, in E. Renan, Discours et Conférences, Paris, Calmann-Lévy.

Rentoul Alexander, 1949. John Frum: Origin of the New Hebrides Movement. Letter to the Editor, Pacific Islands Monthly 19 (6), pp. 31.

Rice Edward, 1974. John Frum He Come. A Polemical Work about a Black Tragedy, New York, Doubleday \& $\mathrm{C}^{\circ}$ Inc. Garden City.

Robbins Joel, 2004. On the Critique in Cargo and the Cargo in Critique: Toward a Comparative Anthropology of Critical Practice, in H. Jebens (ed.), Cargo, Cult \& Culture Critique, Honolulu, Hawai'i University Press, pp. 243-260.

SAHLins Marshall, 1992. The Economics of Develop-Man in the Pacific, Res Anthropology and Aesthetics 21, pp. 12-25.
—, 1999. Two or Three Things I know about Culture, Journal of the Royal Anthropological Institute 5, pp. 399-421.

TABAni Marc, 2008. Une pirogue pour le paradis. Le culte de John Frum à Tanna, Paris, Éditions de la MSH.

_, 2012. What's the Matter with Cargo Cults Today, in M. Tabani \& M. Abong, Kago Kastom Kalja. The Study of Indigenous Movements in Melanesia Today, Marseille, Pacific-Credo Publications, pp. 7-27.

- à paraître. Development, Tourism and Commodification of Cultures in Vanuatu.

Tilley Christopher, 1997. Performing Culture in the Global Village, Critique of Anthropology 17(1), pp. 67-89.

Weber Max, 1995. Économie et société, Paris, Plon. 